\title{
Modeling the Potential Distribution of Three Taxa of Akebia Decne. under Climate Change Scenarios in China
}

\author{
Xiuting Wang $\mathbb{D}^{\mathbb{D}}$, Wenwen Zhang, Xin Zhao, Huiqin Zhu, Limiao Ma, Zengqiang Qian and Zheng Zhang * \\ National Engineering Laboratory for Resource Development of Endangered Chinese Crude Drugs in Northwest \\ China, Key Laboratory of Medicinal Resources and Natural Pharmaceutical Chemistry, The Ministry of \\ Education, Shaanxi Normal University, Xi'an 710119, China; wangxiuting@snnu.edu.cn (X.W.); \\ 17735184595@163.com (W.Z.); 17835417914@163.com (X.Z.); zhuhuiqin@snnu.edu.cn (H.Z.); \\ allen4570@163.com (L.M.); zengqiangqian@snnu.edu.cn (Z.Q.) \\ * Correspondence: zhangzheng@snnu.edu.cn
}

\section{check for} updates

Citation: Wang, X.; Zhang, W.; Zhao, X.; Zhu, H.; Ma, L.; Qian, Z.; Zhang, Z. Modeling the Potential Distribution of Three Taxa of Akebia Decne. under Climate Change Scenarios in China. Forests 2021, 12, 1710.

https://doi.org/10.3390/f12121710

Academic Editors:

Nadezhda Tchebakova and Sergey V. Verkhovets

Received: 14 October 2021

Accepted: 4 December 2021

Published: 6 December 2021

Publisher's Note: MDPI stays neutral with regard to jurisdictional claims in published maps and institutional affiliations.

Copyright: (c) 2021 by the authors. Licensee MDPI, Basel, Switzerland. This article is an open access article distributed under the terms and conditions of the Creative Commons Attribution (CC BY) license (https:/ / creativecommons.org/licenses/by/ $4.0 /)$.
Abstract: Akebia trifoliata (Thunb.) Koidz., Akebia trifoliata subsp. australis (Diels) T. Shimizu and Akebia quinata (Houtt.) Decne. are the source plants of the traditional Chinese medicines AKEBIAE CAULIS and AKEBIAE FRUCTUS, and have high pharmaceutical value. However, the resource reserve of these plants has dramatically declined due to habitat destruction, which has seriously affected their adequate supply and sustainable utilization. A poor knowledge of the potential distribution of these medicinal materials would seriously constrain the protective exploitation of wild resources and the establishment of new cultivations. In this study, based on the scenarios of SSP1-2.6, SSP2-4.5, SSP3-7.0 and SSP5-8.5, the maximum entropy model was used to predict the potential distribution of these three Akebia taxa under current and future (2030s, 2050s, 2070s and 2090s) climate conditions. Our findings showed that the potentially suitable areas of these three Akebia taxa were mainly distributed in China at $101.8-121.9^{\circ} \mathrm{E}$ and $23.5-34.6^{\circ} \mathrm{N}$. Temperature played a more significant role than precipitation in affecting the distribution. The dominant bioclimatic variable that affected the distribution of $A$. trifoliata and $A$. quinata in China was the minimum temperature of the coldest month (BIO06). For A. trifoliata subsp. australis, the mean diurnal range (BIO02) was the dominant variable influencing its distribution. Compared with current conditions, the moderate- and high-suitability areas of these three Akebia taxa were predicted to shrink towards the core areas, while the low-suitability areas were all observed to increase from the 2030s to the 2090s. With the increase in radiative forcing of SSP, the low-impact areas of these three Akebia taxa showed a decreasing trend as a whole. Our results illustrate the impact of climate change on the distribution of Akebia, and would provide references for the sustainable utilization of Akebia's resources.

Keywords: Akebia Decne.; maximum entropy; environmental variables; potential distribution; suitable area

\section{Introduction}

Climate change is one of the crucial factors that affects the distribution of species. According to the Sixth Assessment Report (AR6), "Climate Change 2021: The Physical Science Basis", released by the Intergovernmental Panel on Climate Change (IPCC) in August 2021, the global surface temperature was $1.09{ }^{\circ} \mathrm{C}$ higher in the 2011-2020 period compared to 1850-1900 and climate change will intensify in all regions in the next few decades [1]. Research has shown that global climate change had a major impact on the distribution of species in this period [2,3]. It was estimated that more than $20 \%$ of the world's plant species were facing the threat of extinction [4]. Past studies revealed that since 1990, China's rate of temperature increase has been far greater than the global average [5]. The analysis of the characteristics of climate change from 1960 to 2018 showed that China's precipitation presented an increasing trend [6]. Human activities may determine the future climate direction. Studies showed that the synergistic effects of global climate change 
and human activities may lead to the destruction of species' habitats and increase the risk of species' extinction [7]. In recent decades, land use and land cover change caused by human activities has exerted great impacts on species' distribution and climate change in China. Urban expansion leads to the encroachment of building land into arable land and forest land [8,9]. However, studies also showed that human activities could promote the implementation of ecological protection measures [10]. In the past 30 years, China's vegetation has recovered significantly [11]. Understanding the dynamic changes of species' distribution under climate change is essential since spatial change in climate-driven species' suitable areas would have important implications for developing appropriate protection plans [12]. To raise awareness of climate change, the Coupled Model Intercomparison Project (CMIP) has been implemented by the IPCC since 1995. At present, the Sixth Phase of CMIP (CMIP6) is underway and it developed a set of new scenarios driven by the Shared Socioeconomic Pathways (SSPs), which replaced the Representative Concentration Pathways (RCPs) and has become a key element of climate change assessments [13].

Species distribution and richness are the key issues for the protection of biodiversity under climate change scenarios [14]. The most commonly used numerical tools for evaluating spatial distributions and species richness in space and time are species distribution models (SDMs) [15]. SDMs are based on statistical or biophysical methods; they use the environmental information of known distribution points to infer the environmental requirements for species growth, and then predict the potential distribution of these species $[16,17]$. In recent years, many SDMs, e.g., the Climate Envelope Method (BIOCLIM), the Genetic Algorithm for Rule-set Prediction (GARP) and Maximum Entropy (MAXENT) [18-20], have been employed to predict the potential distribution of species under climate change scenarios. These SDMs only consider the environmental factors that affect the distribution of species, but take no account of factors such as interactions between species, genetics and evolution, and human disturbance [21]. Although only relying on the relationship between species distribution and climate variables may not be sufficient to accurately predict the potential or future distribution of species, SDMs are still the most commonly used methods to assess the impacts on species' potential distribution under climate change scenarios [22]. Since it is difficult to collect species information in the entire range, it is necessary to use SDMs to predict the distribution of species.

The MAXENT model integrates machine learning and the principles of maximum entropy to simulate the potential distribution of species [16], and has proven to be one of the most reliable SDMs due to its predictive power and accuracy [20,23]. Elith et al. [24] showed that MAXENT's predictive performance is consistently competitive with the highest performing methods. Farashi and Alizadeh-Noughani [25] revealed that SDMs' performance strongly depended on the model and MAXENT performed best across all spatial resolutions. Compared with other models, the MAXENT model has the following advantages: (1) only species distribution data and environmental information of the study area are needed [16,26]; (2) an effective maximum entropy algorithm was developed to ensure the optimal probability distribution of species [20]; (3) the algorithm has a concise mathematical definition and is easy to analyze [20]. For many users, MAXENT is likely to be a more accessible way to understand the model than previous ones that rely on machine learning concepts [16]. Due to its advantages, the MAXENT model has been widely applied to predict and evaluate the potential distribution of different species under climate change scenarios [27-29].

The genus Akebia Decne. (Lardizabalaceae) comprises four species, all of which are distributed in China, Japan and the Korean Peninsula in East Asia. Three of the four species (and two associated subspecies) are distributed in China: Akebia quinata (Houtt.) Decne., Akebia longeracemosa Matsumura, Akebia trifoliata (Thunb.) Koidz., Akebia trifoliata subsp. australis (Diels) T. Shimizu and Akebia trifoliata subsp. longisepala H. N. Qin [30]. A. trifoliata, A. trifoliata subsp. australis and A. quinata have been commonly used for thousands of years as source plants of the traditional Chinese medicines AKEBIAE CAULIS and AKEBIAE FRUCTUS to treat fever, facilitate diuresis, and soothe liver stagnation [31]. 
Previous research revealed that the extract of Akebia showed pharmacological activities, specifically clinical antitumor biological activity [32-34]. Lu et al. [35] showed that $A$. trifoliata seed extract could significantly suppress hepatocellular carcinoma cells' viability and proliferation, and then inhibit cell adhesion, migration and invasion. They suggested that an extract of Akebia could be used as a potential candidate to suppress the metastatic progression of hepatocellular carcinoma. As a result of the increasing study of the pharmacological activities of Akebia, such as antitumor activity, the demands for AKEBIAE CAULIS and AKEBIAE FRUCTUS are constantly growing. The relatively long growth cycle coupled with the ever-increasing habitat destruction caused by continuous human activities has made it difficult for Akebia resources to meet the increasing demand of mankind for natural medicine with antitumor activity. This situation has seriously affected its adequate supply and sustainable utilization [36]. At present, these problems might be solved by artificial cultivation. However, the potential distribution of Akebia may change under climate change scenarios in the future. A poor knowledge of the potential distribution of these medicinal materials would seriously constrain the protective exploitation of wild resources and the establishment of new cultivations.

In this study, we predicted the potential distribution of three Akebia taxa under multiple climate change scenarios. The purposes were to: (1) identify the major environmental factors affecting the distribution of Akebia; (2) evaluate the suitability of the potential distribution of these three taxa; (3) predict the impact of climate change on the distribution of Akebia in the future. The findings of this study would provide a basis for the long-term protection and sustainable exploitation of these medicinal resources.

\section{Materials and Methods}

\subsection{Species Occurrence Data}

The occurrence points of the three Akebia taxa were collected from the Chinese Virtual Herbarium (CVH, http:/ /www.cvh.org.cn/, accessed on 3 March 2021), the Global Biodiversity Information Facility (GBIF, http://www.gbif.org/, accessed on 4 March 2021), the National Specimen Information Infrastructure (NSII, http:/ /www.nsii.org.cn/, accessed on 7 March 2021), the Chinese Field Herbarium (CFH, http:/ /www.nsii.org.cn/, accessed on 7 March 2021), the Plant Photo Bank of China (PPBC, http:/ / ppbc.iplant.cn/, accessed on 8 March 2021), the Spacemen Resources Sharing Platform for Education (MNH, http:/ /mnh.scu.edu.cn/, accessed on 8 March 2021), field surveys and relevant literature. All sites were recorded after 1970, and were visually checked to guarantee their quality. Those points with longitude and latitude were used directly, while those with only specific geographical locations were positioned by the Baidu Coordinate Retrieval System ( http:/ / api.map.baidu.com/lbsapi/getpoint/, accessed on 10 March 2021). In this study, 851, 417 and 335 occurrence points of A. trifoliata, A. trifoliata subsp. australis and A. quinata were retrieved, respectively (Figure 1). To avoid the influence of the sampling deviation of occurrence points on prediction accuracy [37], the Trim Duplicates Occurrences function of ENMtools v1.4 (http:/ / purl.oclc.org/enmtools, accessed on 17 March 2021) was used to screen the redundant data. ENMtools matches the size of the environmental factor grid used for analysis, and allows the user to automatically remove duplicate occurrences so that only one point is kept per grid cell, and each remaining point is moved to the center of its grid cell [22,24,38]. Following that, we obtained 670, 335 and 276 nonredundant occurrence points for A. trifoliata, A. trifoliata subsp. australis and A. quinata, respectively. 


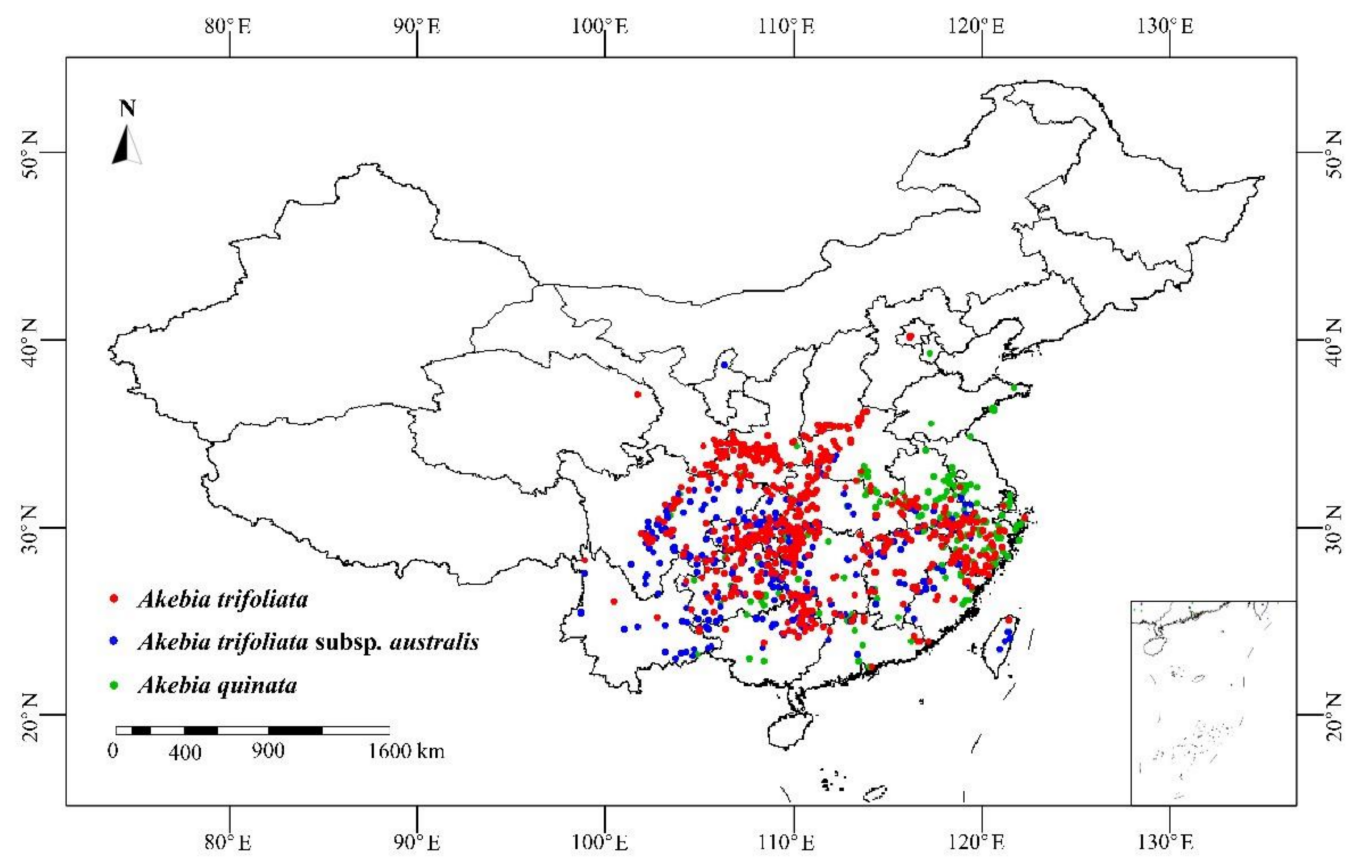

Figure 1. The occurrence data of three species of Akebia.

\subsection{Bioclimatic Variables and Pattern of Scenarios}

The 19 bioclimatic variables used in this study (Table 1) were downloaded from WorldClim (http:/ / www.worldclim.org/, accessed on 7 April 2020) [39]. To ensure the independence of variables and to minimize the impact of multicollinearity and overfitting on the model, the 'Correlation' function in ENMtools v1.4 was used to calculate the Pearson correlation coefficient matrix among the 19 bioclimatic factors. Then, the 19 bioclimatic variables and the occurrence data of Akebia were imported into MaxEnt v3.4.4 (http:/ / biodiversityinformatics.amnh.org/open_source/maxent/, accessed on 25 November 2020) [20], and the percent contributions of bioclimatic variables to the model and the results of Jackknife test were considered comprehensively. We analyzed the major bioclimatic variables impacting the distribution of Akebia, and the relatively more important factors were retained for each pair of highly correlated variables (Pearson, $|\mathrm{r}|>0.80$ ) [40]. The final bioclimatic variables of $A$. trifoliata, A. trifoliata subsp. australis and A. quinata were selected to build the final models.

The AR6 to be released by the IPCC will use the new climatic scenarios in the CMIP6, which combines the RCPs and the SSPs to predict global socio-economic changes up to 2100. Based on SSP1 (Sustainability), SSP2 (Middle of the Road), SSP3 (Regional Rivalry) and SSP5 (Fossil-fuelled Development), CMIP6 updated RCP2.6 (2.6 Wm$\left.{ }^{-2}\right)$, RCP4.5 $\left(4.5 \mathrm{Wm}^{-2}\right), \mathrm{RCP} 3.7\left(3.7 \mathrm{Wm}^{-2}\right)$ and RCP8.5 $\left(8.5 \mathrm{Wm}^{-2}\right)$ to form the SSP1-2.6, SSP24.5, SSP3-7.0 and SSP5-8.5 scenarios [41]. These combinations of scenarios can reflect the combination of radiation forcing and socio-economic scenarios, and make the future scenarios more reasonable [42]. The current (1970-2000) and future data in this study were both downloaded from WorldClim. The future bioclimatic data include four periods, i.e., 2021-2040 (2030s), 2041-2060 (2050s), 2061-2080 (2070s) and 2081-2100 (2090s). Each period covers eight sets of bioclimatic data, corresponding to two general circulation models (i.e., the Second-Generation Beijing Climate Centre Climate System Model (BCC-CSM2-MR) and the Model for Interdisciplinary Research on Climate, Earth System version 2 for long-term simulations (MIROC-ES2L)) and four SSPs (i.e., SSP1-2.6, SSP2-4.5, SSP3-7.0 and SSP5-8.5). In order to reduce the uncertainty of the prediction caused by the single GCM, the final suitability result was obtained by averaging the values of the two GCMs [43]. The finest spatial resolution of these environment layers we could obtain from WorldClim v2.1 was 2.5 arc-minutes. In addition, studies showed that a change in grain size of 10 times does not severely affect predictions from species distribution models [44]. We comprehensively 
considered the study area, computing speed and model accuracy, and decided to use the spatial resolution of 2.5 arc-minutes.

Table 1. Bioclimatic variables and the contribution rates of dominant variables of the three Akebia taxa.

\begin{tabular}{|c|c|c|c|c|c|}
\hline \multirow[b]{2}{*}{ Variable } & \multirow[b]{2}{*}{ Description } & \multirow[b]{2}{*}{ Unit } & \multicolumn{3}{|c|}{ Contribution Rate (\%) } \\
\hline & & & A. trifoliata & $\begin{array}{c}\text { A. trifoliata } \\
\text { subsp. australis }\end{array}$ & A. quinata \\
\hline BIO01 & Annual mean temperature & ${ }^{\circ} \mathrm{C}$ & & & \\
\hline $\mathrm{BIO} 2$ & Mean diurnal range & ${ }^{\circ} \mathrm{C}$ & 16.4 & 89.1 & 15.4 \\
\hline $\mathrm{BIO} 03$ & Isothermality (BIO02/BIO07) & $\%$ & 14.6 & 2.2 & 15.4 \\
\hline $\mathrm{BIO} 04$ & Temperature seasonality & - & 1.5 & 2.0 & 0.9 \\
\hline BIO05 & Max temperature of warmest month & ${ }^{\circ} \mathrm{C}$ & & & 1.9 \\
\hline BIO06 & Min temperature of coldest month & ${ }^{\circ} \mathrm{C}$ & 58.5 & 0.0 & 54.4 \\
\hline $\mathrm{BIO} 07$ & Temperature annual range (BIO05-BIO06) & ${ }^{\circ} \mathrm{C}$ & & & \\
\hline $\mathrm{BIO} 08$ & Mean temperature of wettest quarter & ${ }^{\circ} \mathrm{C}$ & & & \\
\hline BIO09 & Mean temperature of driest quarter & ${ }^{\circ} \mathrm{C}$ & & & \\
\hline BIO10 & Mean temperature of warmest quarter & ${ }^{\circ} \mathrm{C}$ & 5.9 & & \\
\hline BIO11 & Mean temperature of coldest quarter & ${ }^{\circ} \mathrm{C}$ & & & \\
\hline BIO12 & Annual precipitation & $\mathrm{mm}$ & & & \\
\hline $\mathrm{BIO} 13$ & Precipitation of wettest month & $\mathrm{mm}$ & & & \\
\hline BIO14 & Precipitation of driest month & $\mathrm{mm}$ & 1.0 & 0.1 & 2.6 \\
\hline BIO15 & Precipitation seasonality & $\mathrm{mm}$ & 1.9 & 5.1 & 8.5 \\
\hline BIO16 & Precipitation of wettest quarter & $\mathrm{mm}$ & & & \\
\hline BIO17 & Precipitation of driest quarter & $\mathrm{mm}$ & & & \\
\hline BIO18 & Precipitation of warmest quarter & $\mathrm{mm}$ & 0.3 & 0.2 & 0.8 \\
\hline BIO19 & Precipitation of coldest quarter & $\mathrm{mm}$ & & 1.3 & \\
\hline
\end{tabular}

\subsection{Optimization of Model Parameters}

The feature class and regularization multiplier are considered to be two important parameters that affect the accuracy of modelling [45]. In order to select the optimal model, the $\mathrm{R}$ v3.6.3 program and the 'kuenm' package [46] were used to combine 15 feature classes (incl. lineal $(\mathrm{L})$, quadratic $(\mathrm{Q})$, product $(\mathrm{P})$ and hinge $(\mathrm{H})$ ) and 40 regularization multipliers (from 0 to 4.0, at intervals of 0.1). Finally, a total of 600 candidate models were generated. All the models were evaluated on the basis that the omission rate was less than 0.05 and that the delta AICc (Akaike information criterion corrected for small sample size) was not higher than 2 [46]. At last, the feature classes of $\mathrm{QP}, \mathrm{L}$ and $\mathrm{QP}$ and the regularization multipliers of $0.4,0.1$ and 0.1 were selected as the final parameters of $A$. trifoliata, A. trifoliata subsp. australis and A. quinata, respectively. In addition, $25 \%$ of the occurrence data were randomly selected as test sets, and $75 \%$ of them as training sets. The model was replicated ten times following the 'Subsample' approach. The output format was 'Logistic' and the maximum iteration was set to 5000. Other parameters were set to default. The value of the area under the receiver operating characteristic (ROC) curve (AUC) was used to assess the accuracy of the MAXENT models [47]. AUC values range between 0 and 1 , and the closer the value to 1 , the better the performance of the model. The accuracy of the model is classified into five grades: Fail (0.5-0.6), Poor (0.6-0.7), Fair (0.7-0.8), Good (0.8-0.9) and Excellent (0.9-1.0), and the performance of the model is considered no better than random if the value is less than 0.5 [48]. Partial ROC was developed to counteract the differences or error of the AUC curve and is used to verify that a model's results are not equal to random values, which is indicated if the model presents a non-significant $p$-value [46,49]. The Partial ROC function of the NicheToolBox program (http:/ / shiny.conabio.gob.mx:3838/nichetoolb2/, accessed on 27 November 2021) was used to undertake the partial ROC test to ensure the greater robustness of the best model obtained; the criteria to select the best model was a significant value in the partial ROC test $(p \leq 0.5)$ [50].

\subsection{Classification of Suitable Area}

In this study, DIVA-GIS v7.5 software was used to manipulate the prediction layers of current (1970-2000), future (2030s, 2050s, 2070s and 2090s) and low-impact areas. The division of suitable areas took the threshold as the limit, with those below and above the 
threshold being defined as unsuitable and suitable areas, respectively. The selection of the final threshold should be determined according to the research object and needs. In the present study, "Balance training omission, predicted area and threshold value", a relatively loose threshold, was applied as the criterion for the classification of suitable/unsuitable areas of the three Akebia taxa [51]. Finally, the suitability maps were divided into four grades: unsuitable area, low-suitability area, moderate-suitability area and high-suitability area. The corresponding values were as follows: A. trifoliata $(0-0.0316,0.0316-0.3544$, $0.3544-0.6772,0.6772-1)$, A trifoliata subsp. australis $(0-0.0447,0.0447-0.3631,0.3631-0.6816$, $0.6816-1)$, and A. quinata (0-0.0237, 0.0237-0.3491, 0.3491-0.6746, 0.6746-1).

The area less affected by climate change was referred to as the low-impact area. The areas between 0 and the threshold were treated as unsuitable areas, represented by 0 , while those between the threshold and 1 were treated as the suitable areas, represented by 1 . In this study, DIVA-GIS v7.5 was used to stack the binary layers of suitable areas in different periods and the completely overlapping parts were used to make the distribution map of low-impact area.

\section{Results}

\subsection{Contribution of Bioclimatic Variables and Model Accuracy}

After the correlation analysis of the 19 bioclimatic variables, eight variables were selected to construct models for A. trifoliata, A. trifoliata subsp. australis and A. quinata, respectively. The accuracy of MAXENT models is often evaluated by AUC values. In this study, the AUC values for A. trifoliata, A. trifoliata subsp. australis and A. quinata were 0.943 , 0.921 and 0.957 , respectively (Figure 2), indicating excellent accuracy of the models. The best models of these three species were all significant (partial ROC $=0$ ). This means that the models obtained were better than a random model (partial ROC $=0$ ). All of these suggested that the model could be used to predict the distributions of these three Akebia taxa.

A

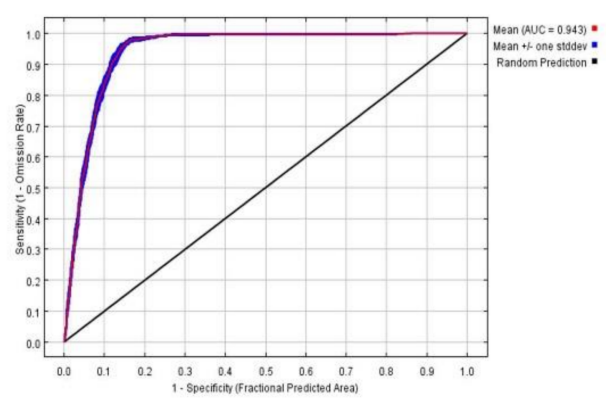

B

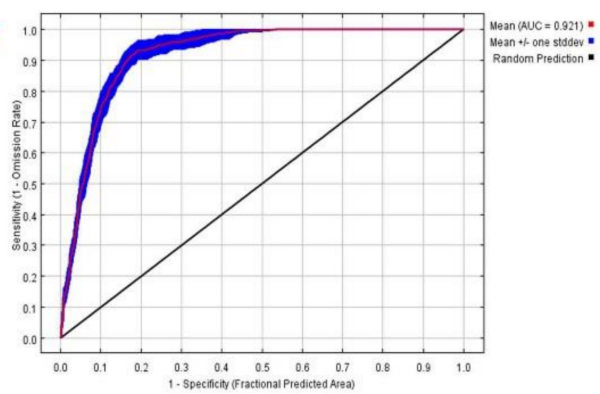

$\mathrm{C}$

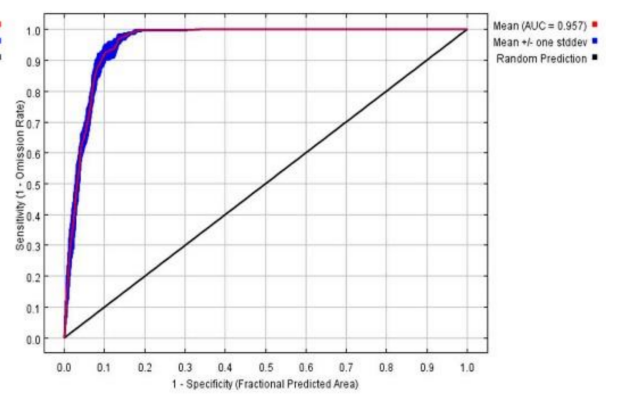

Figure 2. Prediction validation with receiver operator characteristic (ROC) curves using MaxEnt. AUC: the area under the curve. (A) A. trifoliata; (B) A. trifoliata subsp. australis; (C) A. quinata.

The importance of bioclimatic variables to species distribution was evaluated by the percent contribution (Table 1) and the results of Jackknife tests (Figure 3). Minimum temperature of coldest month (BIO06), mean diurnal range (BIO02) and isothermality (BIO03) were the dominant bioclimatic variables affecting the potential distribution of A. trifoliata and A. quinata, with their cumulative contribution rates being 89.5 and $85.2 \%$, respectively. BIO02 (89.1\%) occupied the most important position among the factors affecting the potential distribution of $A$. trifoliata subsp. australis. 

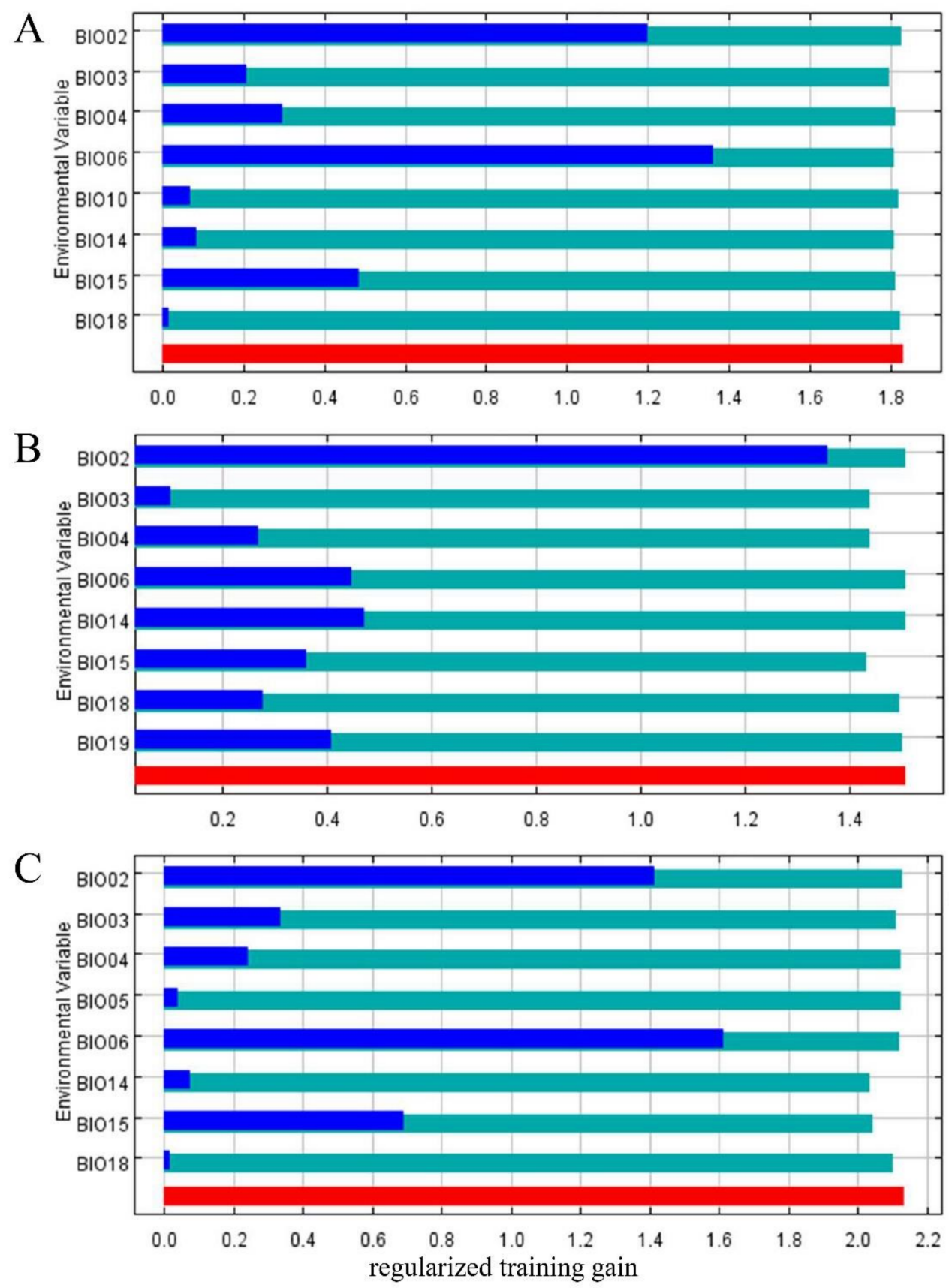

With all variables With only variables Without variables

Figure 3. Jackknife test for evaluation of the relative importance of major bioclimatic variables for three Akebia taxa. (A) A. trifoliata; (B) A. trifoliata subsp. australis; (C) A. quinata.

The Jackknife analysis of bioclimatic variables revealed that BIO02 and BIO06 were the two most important predictors of $A$. trifoliata and $A$. quinata's potential distributions (Figure 3), indicating that these contain the more gainful and characteristic information in terms of defining distributions. In Figure 3B, BIO03 was the variable with the least gain, but the most unique information would have been lost if it was removed. The gain of precipitation of driest month (BIO14), precipitation seasonality (BIO15) and precipitation of coldest quarter (BIO18) would have been decreased if they were omitted from the data shown in Figure 3C, which demonstrated that BIO14, BIO15 and BIO18 contained important information that could not be explained by other variables in the predicted of potential distribution of $A$. quinata. 


\subsection{The Current Potential Distributions of the Three Akebia Taxa}

MAXENT modelling was employed to predict the current potential distribution areas of A. trifoliata, A. trifoliata subsp. australis and A. quinata (Figure 4). Our results demonstrated that the moderate- and high-suitability areas of these three taxa were mainly distributed in China at $101.8-121.9^{\circ} \mathrm{E}$ and $23.5-34.6^{\circ} \mathrm{N}$. The high-suitability areas of A. trifoliata subsp. australis were more concentrated and that of A. trifoliata and A. quinata were more fragmented.
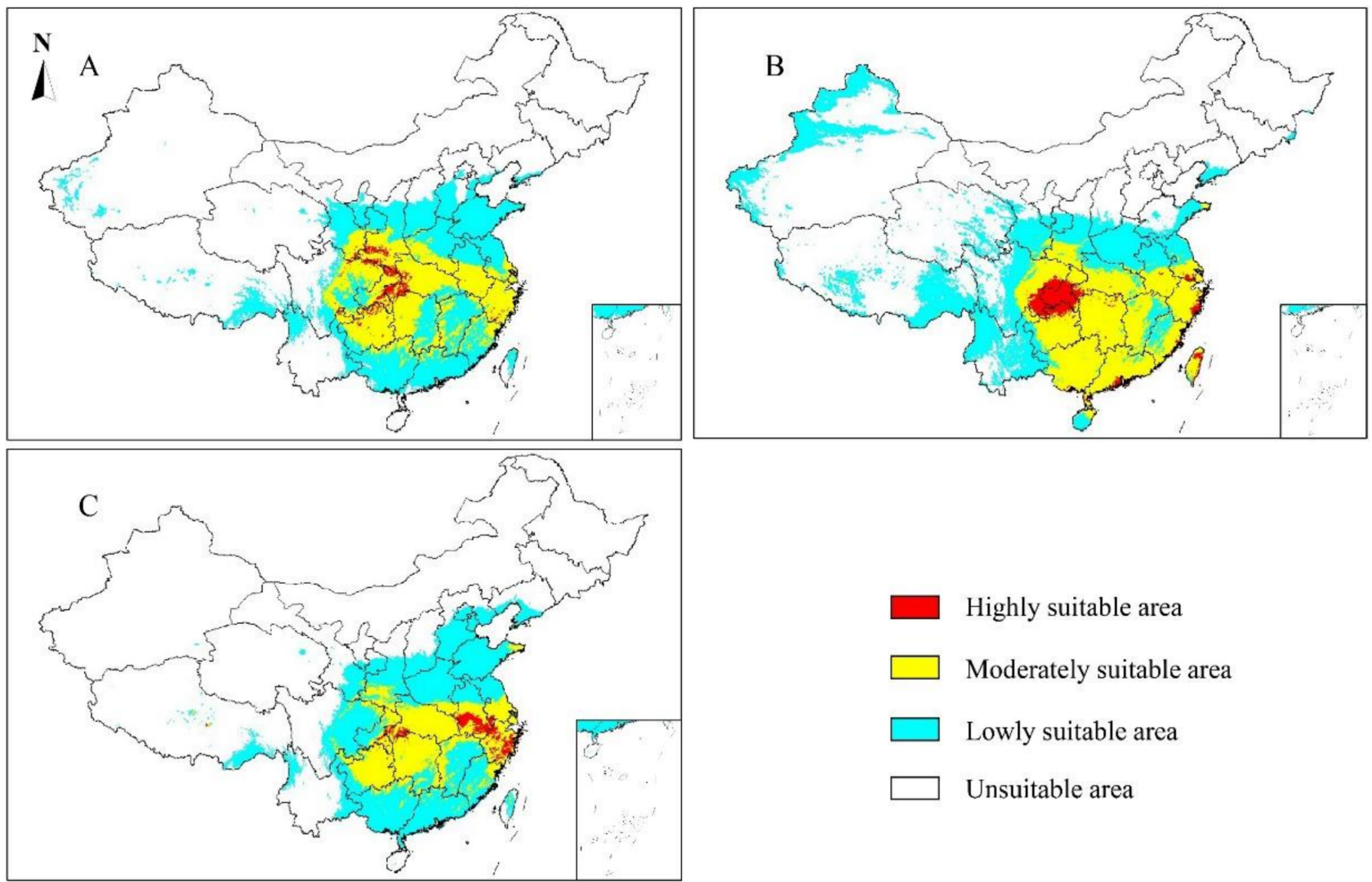

$\square$ Highly suitable area

Moderately suitable area

Lowly suitable area

Unsuitable area

Figure 4. Potential distributions of (A) A. trifoliata, (B) A. trifoliata subsp. australis and (C) A. quinata under the current climatic condition in China.

Under the current climate condition, various suitable areas of A. trifoliata subsp. australis were all the largest among these three Akebia taxa. The high-suitability areas of A. trifoliata subsp. australis $\left(18.14 \times 10^{4} \mathrm{~km}^{2}\right)$ were more than twice as large as A. trifoliata $\left(8.00 \times 10^{4} \mathrm{~km}^{2}\right)$ and A. quinata $\left(8.77 \times 10^{4} \mathrm{~km}^{2}\right)$. Although the high-suitability area of A. quinata was $0.77 \times 10^{4} \mathrm{~km}^{2}$ larger than that of $A$. trifoliata, the total suitable area of $A$. quinata was $17.43 \times 10^{4} \mathrm{~km}^{2}$ smaller than that of A. trifoliata (Table 2).

\subsection{The Potential Future Distributions of the Three Akebia Taxa}

Potential distributions of the different suitable areas for these three Akebia taxa in China in four future periods (2030s, 2050s, 2070s and 2090s) and under four shared socioeconomic pathways (SSP1-2.6, SSP2-4.5, SSP3-7.0 and SSP5-8.5) were analyzed (Figures 5-7, Table 2). 
Table 2. Predicted suitable areas under different climatic scenarios of the three Akebia taxa.

\begin{tabular}{|c|c|c|c|c|c|c|c|c|c|c|}
\hline \multirow{2}{*}{ Taxa } & \multirow{2}{*}{\multicolumn{2}{|c|}{ Climate Scenarios }} & \multicolumn{2}{|c|}{$\begin{array}{c}\text { Total Suitable } \\
\text { Area }\end{array}$} & \multicolumn{2}{|c|}{$\begin{array}{c}\text { Low-Suitability } \\
\text { Area }\end{array}$} & \multicolumn{2}{|c|}{$\begin{array}{c}\text { Moderate-Suitability } \\
\text { Area }\end{array}$} & \multicolumn{2}{|c|}{$\begin{array}{c}\text { High-Suitability } \\
\text { Area }\end{array}$} \\
\hline & & & $\begin{array}{c}\text { Area } \\
\left(\times 10^{4} \mathrm{~km}^{2}\right)\end{array}$ & $\begin{array}{l}\text { Trend } \\
(\%)^{1}\end{array}$ & $\begin{array}{c}\text { Area } \\
\left(\times 10^{4} \mathrm{~km}^{2}\right)\end{array}$ & $\begin{array}{l}\text { Trend } \\
(\%)^{1}\end{array}$ & $\begin{array}{c}\text { Area } \\
\left(\times 10^{4} \mathrm{~km}^{2}\right)\end{array}$ & $\begin{array}{c}\text { Trend } \\
(\%)^{1}\end{array}$ & $\begin{array}{c}\text { Area } \\
\left(\times 10^{4} \mathrm{~km}^{2}\right)\end{array}$ & $\begin{array}{l}\text { Trend } \\
(\%)^{1}\end{array}$ \\
\hline \multirow{17}{*}{ A. trifoliata } & \multicolumn{2}{|c|}{ 1970-2000 } & 290.34 & - & 169.98 & - & 112.35 & - & 8.00 & - \\
\hline & \multirow{5}{*}{ SSP1-2.6 } & $2030 \mathrm{~s}$ & 302.86 & 4.31 & 219.02 & 28.85 & 79.39 & -29.34 & 4.44 & -44.47 \\
\hline & & $2050 \mathrm{~s}$ & 300.66 & 3.56 & 236.48 & 39.12 & 60.79 & -45.89 & 3.39 & -57.65 \\
\hline & & $2070 \mathrm{~s}$ & 298.33 & 2.75 & 237.87 & 39.94 & 58.19 & -48.21 & 2.27 & -71.60 \\
\hline & & $2090 \mathrm{~s}$ & 311.74 & 7.37 & 241.49 & 42.07 & 66.33 & -40.96 & 3.93 & -50.94 \\
\hline & & $2030 \mathrm{~s}$ & 297.21 & 2.37 & 204.49 & 20.30 & 87.41 & -22.20 & 5.31 & -33.69 \\
\hline & \multirow{4}{*}{ SSP2-4.5 } & $2050 \mathrm{~s}$ & 311.90 & 7.34 & 254.14 & 49.51 & 55.42 & -50.67 & 2.35 & -70.64 \\
\hline & & $2070 \mathrm{~s}$ & 309.67 & 6.66 & 263.29 & 54.89 & 44.88 & -60.06 & 1.51 & -81.16 \\
\hline & & $2090 \mathrm{~s}$ & 310.75 & 7.03 & 267.15 & 57.16 & 42.69 & -62.00 & 0.91 & -88.57 \\
\hline & & $2030 s$ & 298.13 & 2.68 & 212.65 & 25.10 & 81.79 & -27.20 & 3.70 & -53.82 \\
\hline & \multirow{4}{*}{ SSP3-7.0 } & $2050 \mathrm{~s}$ & 307.06 & 5.76 & 244.49 & 43.83 & 59.97 & -46.62 & 2.61 & -67.44 \\
\hline & & 2070 s & 311.36 & 7.24 & 269.46 & 58.52 & 40.65 & -63.82 & 1.25 & -84.39 \\
\hline & & 2090 s & 326.43 & 12.43 & 292.41 & 72.02 & 33.27 & -70.38 & 0.74 & -90.71 \\
\hline & & $2030 \mathrm{~s}$ & 311.47 & 7.28 & 232.94 & 37.03 & 74.18 & -33.98 & 4.36 & -45.55 \\
\hline & \multirow{3}{*}{ SSP5-8.5 } & $2050 \mathrm{~s}$ & 304.61 & 4.92 & 257.62 & 51.55 & 45.54 & -59.47 & 1.46 & -81.77 \\
\hline & & $2070 \mathrm{~s}$ & 317.12 & 9.22 & 279.22 & 64.26 & 36.77 & -67.27 & 1.13 & -85.88 \\
\hline & & 2090 s & 314.46 & 8.31 & 294.75 & 73.40 & 19.55 & -82.06 & 0.15 & -98.07 \\
\hline \multirow{17}{*}{$\begin{array}{l}\text { A. trifoliata } \\
\text { subsp. } \\
\text { australis }\end{array}$} & \multicolumn{2}{|c|}{ 1970-2000 } & 352.82 & - & 194.98 & - & 139.69 & - & 18.14 & - \\
\hline & \multirow{5}{*}{ SSP-1-26 } & $2030 s$ & 355.57 & 0.78 & 203.90 & 4.57 & 134.72 & -3.56 & 16.95 & -6.55 \\
\hline & & $2050 \mathrm{~s}$ & 353.77 & 0.27 & 205.49 & 5.39 & 132.99 & -4.80 & 15.29 & -15.70 \\
\hline & & $2070 \mathrm{~s}$ & 359.82 & 1.98 & 225.83 & 18.82 & 123.96 & -11.27 & 10.04 & -44.69 \\
\hline & & 2090 s & 359.42 & 1.87 & 212.92 & 9.20 & 129.32 & -7.42 & 17.17 & -5.34 \\
\hline & & 2030 s & 353.38 & 0.16 & 195.51 & 0.27 & 141.63 & -1.38 & 16.24 & -10.46 \\
\hline & \multirow{4}{*}{ SSP2-4.5 } & 2050 s & 362.62 & 2.78 & 221.19 & 13.44 & 130.83 & -6.34 & 10.59 & -41.60 \\
\hline & & $2070 \mathrm{~s}$ & 355.61 & 0.79 & 228.05 & 16.96 & 118.39 & -15.25 & 9.17 & -49.44 \\
\hline & & $2090 s$ & 361.83 & 2.55 & 231.03 & 18.49 & 122.58 & -12.25 & 8.21 & -54.76 \\
\hline & & 2030 s & 354.78 & 0.56 & 200.40 & 2.78 & 137.89 & -1.29 & 16.49 & -9.11 \\
\hline & \multirow{3}{*}{ SSP3-7.0 } & 2050 s & 357.44 & 1.31 & 207.32 & 6.33 & 135.48 & -3.02 & 14.64 & -19.30 \\
\hline & & $2070 \mathrm{~s}$ & 357.35 & 1.28 & 217.96 & 11.78 & 128.72 & -7.86 & 10.68 & -41.14 \\
\hline & & $2090 \mathrm{~s}$ & 358.05 & 1.48 & 215.55 & 10.55 & 132.85 & -4.90 & 9.65 & -46.83 \\
\hline & & 2030 s & 361.08 & 2.34 & 210.94 & 8.18 & 134.78 & -3.51 & 15.36 & -15.32 \\
\hline & & $2050 \mathrm{~s}$ & 358.10 & 1.50 & 219.46 & 12.56 & 128.95 & -7.69 & 9.69 & -46.60 \\
\hline & SSP5-8.5 & 2070 s & 359.15 & 1.79 & 223.44 & 14.60 & 122.43 & -12.36 & 13.27 & -26.84 \\
\hline & & $2090 \mathrm{~s}$ & 341.54 & -3.20 & 241.67 & 23.95 & 94.42 & -32.41 & 5.46 & -69.93 \\
\hline & 197 & & 272.91 & - & 176.02 & - & 88.12 & - & 8.77 & - \\
\hline & & $2030 s$ & 280.92 & 2.94 & 214.54 & 21.88 & 64.04 & -27.33 & 2.35 & -73.20 \\
\hline & & 2050 s & 280.88 & 2.92 & 242.58 & 37.81 & 37.92 & -56.97 & 0.38 & -95.61 \\
\hline & SSP-1-26 & $2070 \mathrm{~s}$ & 279.27 & 2.33 & 230.21 & 30.97 & 47.66 & -45.92 & 1.39 & -84.09 \\
\hline & & $2090 \mathrm{~s}$ & 287.15 & 5.22 & 225.65 & 28.19 & 59.76 & -32.18 & 1.74 & -80.20 \\
\hline & & 2030 s & 279.03 & 2.24 & 205.40 & 116.69 & 70.50 & -19.99 & 3.12 & -64.39 \\
\hline & & $2050 \mathrm{~s}$ & 294.41 & 7.88 & 236.06 & 34.11 & 56.41 & -35.99 & 1.95 & -77.75 \\
\hline & SSP2-4.5 & $2070 \mathrm{~s}$ & 297.71 & 9.09 & 257.02 & 46.01 & 39.42 & -55.26 & 1.26 & -85.59 \\
\hline A. quinata & & 2090 s & 296.39 & 8.60 & 259.49 & 47.42 & 36.10 & -59.03 & 0.80 & -90.89 \\
\hline & & 2030 s & 285.15 & 4.48 & 198.59 & 12.82 & 83.90 & -4.78 & 2.66 & -69.68 \\
\hline & & $2050 \mathrm{~s}$ & 294.68 & 7.98 & 232.08 & 34.85 & 61.33 & -30.40 & 1.27 & -85.53 \\
\hline & SSP3-7.0 & $2070 \mathrm{~s}$ & 289.12 & 5.94 & 256.19 & 45.55 & 31.82 & -63.88 & 1.10 & -87.49 \\
\hline & & $2090 \mathrm{~s}$ & 305.92 & 12.10 & 276.44 & 57.05 & 28.50 & -67.66 & 0.98 & -88.81 \\
\hline & & 2030 s & 287.89 & 5.49 & 196.71 & 11.75 & 85.95 & -2.47 & 5.23 & -40.36 \\
\hline & & $2050 \mathrm{~s}$ & 291.20 & 6.70 & 252.81 & 43.62 & 37.49 & -57.46 & 0.91 & -89.62 \\
\hline & SSP5-8.5 & 2070 s & 291.93 & 6.97 & 266.69 & 51.51 & 24.58 & -72.10 & 0.66 & -92.47 \\
\hline & & $2090 \mathrm{~s}$ & 254.18 & -6.86 & 246.91 & 40.27 & 6.85 & -92.23 & 0.42 & -95.22 \\
\hline
\end{tabular}

${ }^{1}$ The percentage of loss (-) or gain (+) of the predicted area relative to the area of current climatic condition.

In terms of the future conditions, the moderate- and high-suitability areas of these three Akebia taxa were predicted to contract or expand towards the core. The low-suitability areas of these three taxa were predicted to increase compared with their corresponding areas under current climate condition. A trifoliata showed the largest increase $(73.4 \%)$ during the 2090s under the scenario of SSP5-8.5. As far as the moderate- and high-suitability areas were concerned, the areas were predicted to decline to varying degrees in different periods and under different pathways, but some of the high-suitability areas were predicted to still maintain their original states when responding to climate change, such as the areas of A. trifoliata located $106.5-110.2^{\circ} \mathrm{E}$ and $33.5-34.0^{\circ} \mathrm{N}$, the areas of $A$. trifoliata subsp. australis located $104.7-107.9^{\circ} \mathrm{E}$ and $28.2-30.5^{\circ} \mathrm{N}$. 


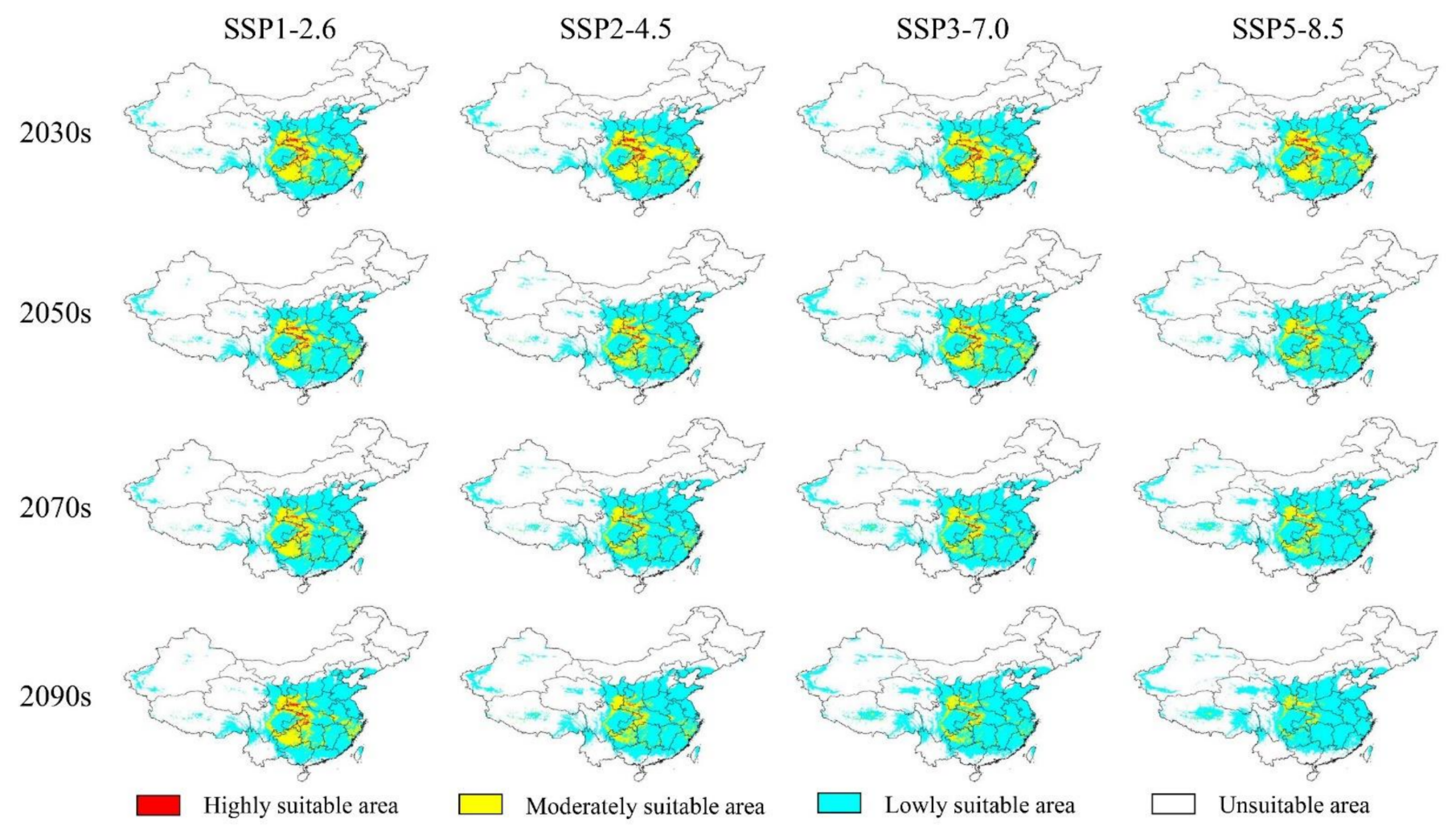

Figure 5. Predicted future potential distribution of $A$. trifoliata under different scenarios in China. The 2030s, 2050s, 2070s and 2090s represent four periods. SSP1-2.6, SSP2-4.5, SSP3-7.0 and SSP5-8.5 represent four Shared Socioeconomic Pathways (SSPs).

2030s

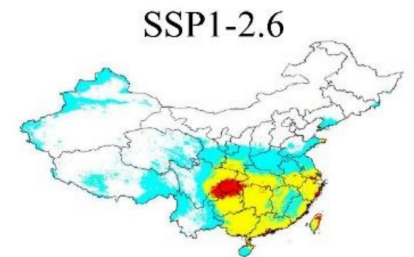

2050s

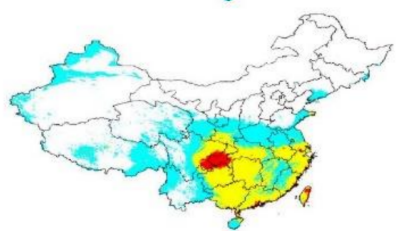

2070 s

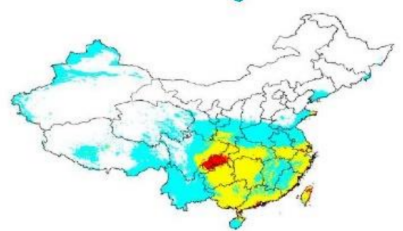

2090 s

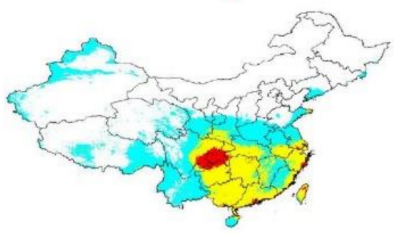

Highly suitable area
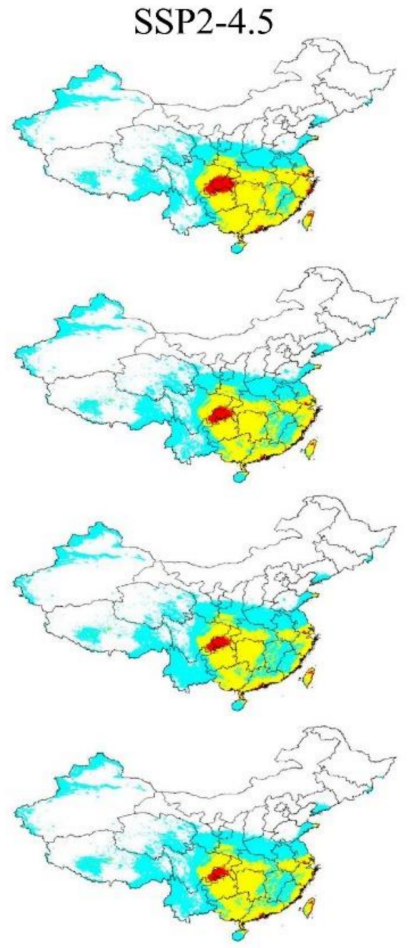

Moderately suitable area
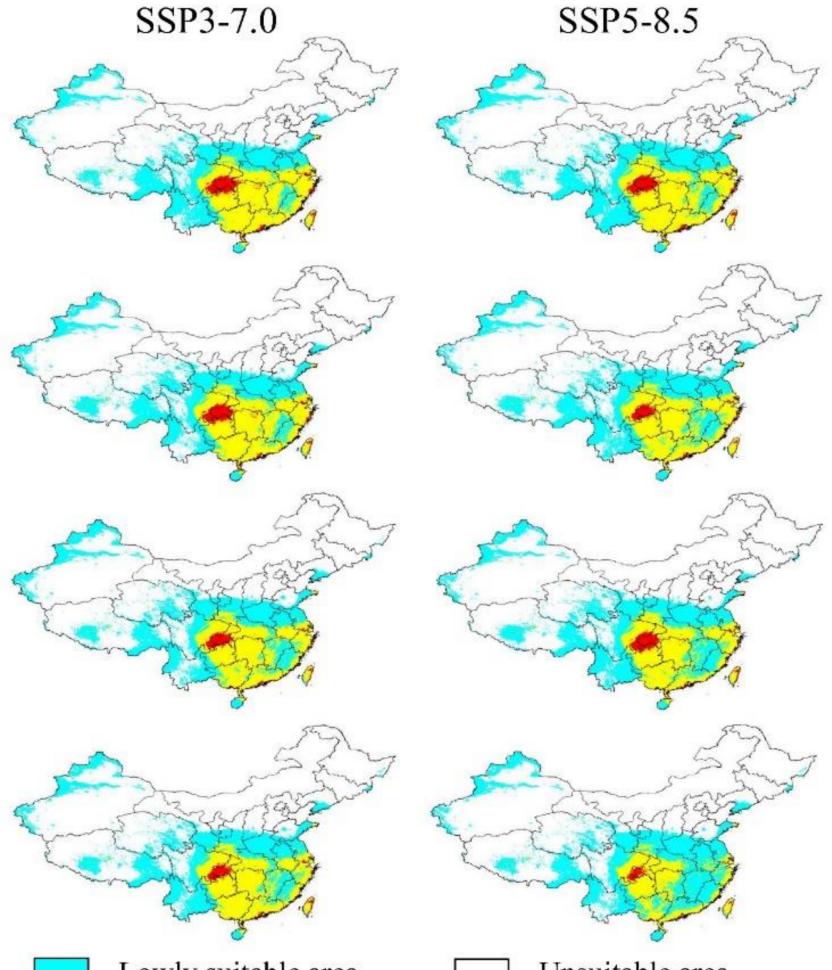

Figure 6. Predicted future potential distribution of A. trifoliata subsp. australis under different scenarios in China. The 2030s, 2050s, 2070s and 2090s represent four periods. SSP1-2.6, SSP2-4.5, SSP3-7.0 and SSP5-8.5 represent four Shared Socioeconomic Pathways (SSPs). 


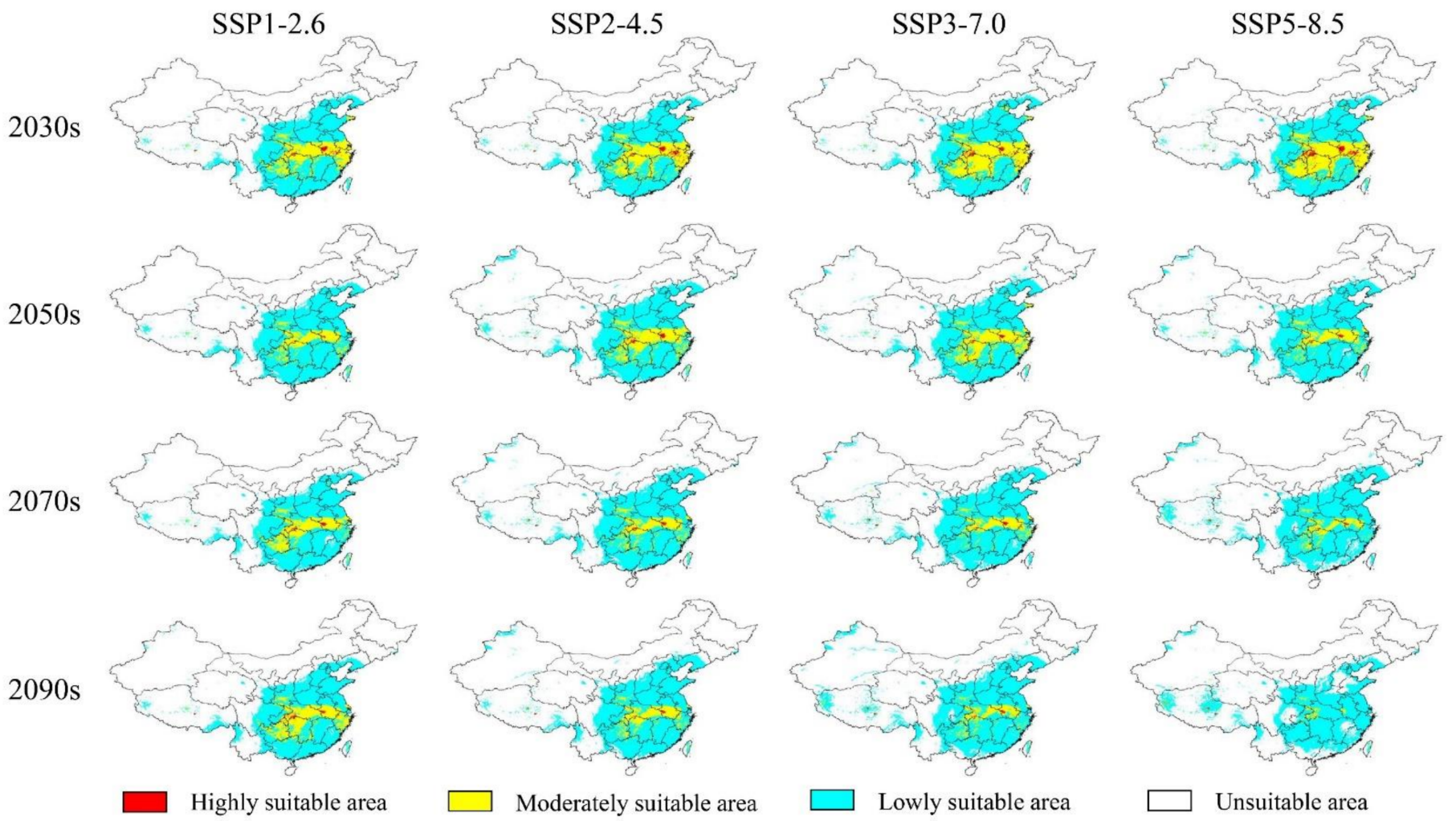

Figure 7. Predicted potential distribution of A. quinata under different scenarios in China. The 2030s, 2050s, 2070s and 2090s represent four future periods. SSP1-2.6, SSP2-4.5, SSP3-7.0 and SSP5-8.5 represent four Shared Socioeconomic Pathways (SSPs).

As for A. trifoliata, the high-suitability areas were predicted only $1.93 \times 10^{4} \mathrm{~km}^{2}$, accounted for $1.93 \%$ of the current distribution, which was the smallest among these three Akebia taxa during the period of the 2090s under SSP5-8.5. Under SSP1-2.6, the moderateand high-suitability areas of $A$. quinata were predicted to decrease greatly from the 2030s to the 2050s, and then to adopt an increasing trend. As an illustration, the moderate-suitability area during the $2050 \mathrm{~s}\left(37.92 \times 10^{4} \mathrm{~km}^{2}\right)$ was predicted to decrease by $26.12 \times 10^{4} \mathrm{~km}^{2}$ compared with that of the 2030s $\left(64.04 \times 10^{4} \mathrm{~km}^{2}\right)$. By contrast, the moderate- and highsuitability areas of $A$. trifoliata subsp. australis were more complex under different climate scenarios. The areas were predicted to reach the largest under SSP2-4.5 during the 2030s $\left(141.63 \times 10^{4} \mathrm{~km}^{2}\right)$ and under SSP1-2.6 during the 2050s $\left(17.17 \times 10^{4} \mathrm{~km}^{2}\right)$, respectively.

MAXENT modelling was also employed to predict the low-impact areas of these three Akebia taxa in China. From the results, it was clear that with the increase in the radiative forcing of SSP from SSP1-2.5 to SSP5-8.5, the low-impact areas of these three Akebia taxa showed a decreasing trend as a whole. A further finding was that these low-impact areas were predicted to mainly reduce in the $21.6-24.3^{\circ} \mathrm{N}$ region (Figure 8 ). The models showed that under the SSP5-8.5 climate scenario, the low-impact areas of A. trifoliata and A. quinata were predicted to decline the most compared with current conditions, with decreases of $43.16 \times 10^{4} \mathrm{~km}^{2}$ and $61.51 \times 10^{4} \mathrm{~km}^{2}$, respectively. As for A. trifoliata subsp. australis, the low-impact area displayed a relatively slight decreasing trend, with the maximum reduction of $7.53 \%$ from current conditions (Table 3). 


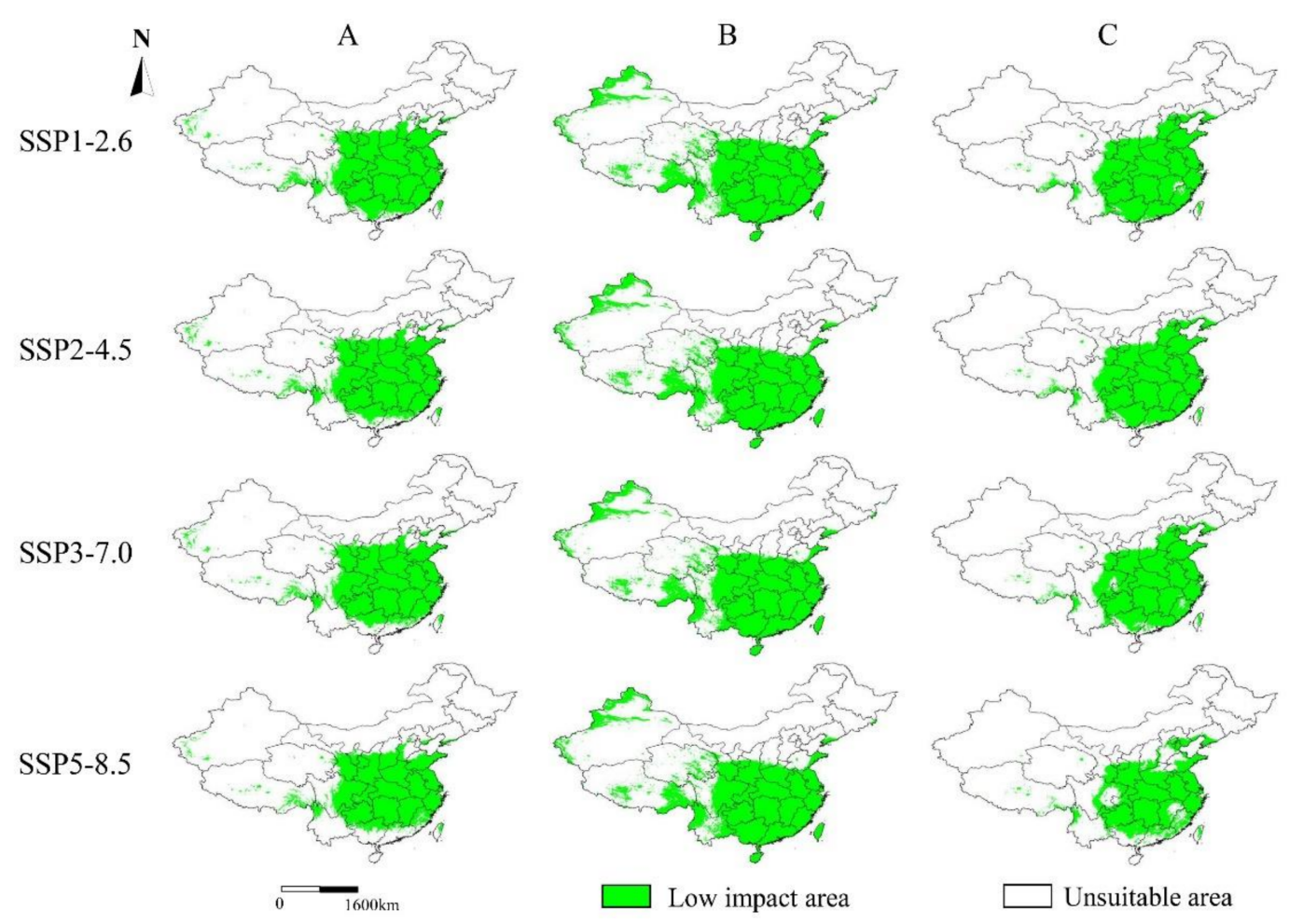

Figure 8. Predicted low-impact areas of three Akebia taxa in China. SSP1-2.6, SSP2-4.5, SSP3-7.0 and SSP5-8.5 represent four Shared Socioeconomic Pathways (SSPs). (A) A. trifoliata; (B) A. trifoliata subsp. australis; (C) A. quinata.

Table 3. Predicted low-impact areas of the three Akebia taxa under different climatic scenarios.

\begin{tabular}{|c|c|c|c|c|}
\hline Taxa & Scenarios & Area $\left(\times 10^{4} \mathrm{~km}^{2}\right)$ & Ratio (\%) $\mathrm{A}^{1}$ & Ratio (\%) B ${ }^{2}$ \\
\hline \multirow{4}{*}{ A. trifoliata } & SSP1-2.6 & 276.81 & $28.83 \%$ & $95.34 \%$ \\
\hline & SSP2-4.5 & 267.62 & $27.88 \%$ & $92.18 \%$ \\
\hline & SSP3-7.0 & 260.25 & $27.11 \%$ & $89.64 \%$ \\
\hline & SSP5-8.5 & 247.18 & $25.75 \%$ & $85.14 \%$ \\
\hline \multirow{4}{*}{$\begin{array}{l}\text { A. trifoliata subsp. } \\
\text { australis }\end{array}$} & SSP1-2.6 & 331.29 & $34.51 \%$ & $93.90 \%$ \\
\hline & SSP2-4.5 & 326.27 & $33.99 \%$ & $92.48 \%$ \\
\hline & SSP3-7.0 & 327.28 & $34.09 \%$ & $92.76 \%$ \\
\hline & SSP5-8.5 & 326.28 & $33.99 \%$ & $92.48 \%$ \\
\hline \multirow{4}{*}{ A. quinata } & SSP1-2.6 & 263.81 & $27.48 \%$ & $96.67 \%$ \\
\hline & SSP2-4.5 & 261.97 & $27.29 \%$ & $95.99 \%$ \\
\hline & SSP3-7.0 & 252.90 & $26.34 \%$ & $92.67 \%$ \\
\hline & SSP5-8.5 & 211.40 & $22.02 \%$ & $77.46 \%$ \\
\hline
\end{tabular}

${ }^{1}$ The percentage of low-impact area relative to the area of China. ${ }^{2}$ The percentage of low-impact area relative to the area of current climatic conditions.

\section{Discussion}

\subsection{Optimization of MAXENT Model}

The species distribution model is a powerful tool for evaluating the distribution and abundance of species in space and time [40]. As a model that has been widely used, MAXENT showed advantages in predicting the distribution of species. However, the relatively high predictive performance of the model allows users to adopt model results directly without analysis or only focus on the complexity of the model itself, and then ignore the necessity of model optimization [52]. An unoptimized model may express high accuracy in modelling, but over-fitting would occur and result in inaccurate prediction and wrong niche assessment, and eventually may mislead policy makers.

Previous reports showed that the factors that affect the accuracy of the prediction of MAXENT model include sample selection, model complexity and the evaluation of 
predictive ability [53]. The occurrence records and sample size of the target species are vital to the construction of models. The occurrence points not only contain the geographic information, but also contain the ecological spatial information of these species. According to Hernandez et al. [54] and Hirzel et al. [55], the success of model predictions may increase along with sample size. Accordingly, as many species distribution data as possible in a wider range were collected in this study to reduce inaccurate predictions caused by incomplete data. A total of 851, 417 and 335 occurrence points of A. trifoliata, A. trifoliata subsp. australis and A. quinata were collected, respectively. In addition to the sample size, the influence of spatial deviation is also an important factor affecting modelling. Philips et al. [37] explored the influence of spatial bias on the accuracy of models, and suggested that improving the understanding of the impact of bias in the survey space and using the optimization model would greatly improve the prediction results of species distribution. Kramer-Schadt et al. [56] compared the difference between the spatial filtering and background manipulation with bias files, and showed that the former performs better than the latter in reducing omission errors and misjudgement errors. As a result, we excluded the records that were without detailed geographical locations and removed the redundant points using the ENMtools program, which could automatically match the grid size of environmental factors and delete redundant data in the same grid.

When constructing the niche model, the complexity of the model is also an aspect that cannot be ignored. The three main factors that affect the complexity of the MAXENT model are the combination of bioclimatic variables, feature classes and regularization multipliers. The 19 bioclimatic variables were derived from temperature and precipitation, and the multicollinearity among them would affect the predicted results. The correlation analysis and Jackknife approach were used to assess the importance of variables. One variable at a time was excluded when running the model. If a variable was affected by other variables in explaining the species distribution, then the gain of this variable would change little after being eliminated [57]. In this study, the intercorrelations of 19 bioclimatic variables and the results of Jackknife test were considered comprehensively, and only the one with relatively high importance was retained for each pair of highly correlated variables $(|r| \geq 0.8)$. In addition, the predictive performance of the model was also affected by feature classes and regularization multipliers. Although the MaxEnt software could automatically adjust the coefficients, and reduce the impact of over-fitting to a large extent [58], many studies have shown that it is necessary to select parameters for different species separately [22,59]. We selected the optimized parameters for model construction from 15 feature classes and 40 regularization multipliers to reduce the deviation and evaluated the models on the basis of the omission rate and the delta AICc. Along with the reducing of environmental variables and the selecting of optimal parameters, the complexity of the models were also reduced.

The AUC value was used to assess the predictive ability of the MAXENT models. The results showed that the AUC values of A. trifoliata (0.943), A. trifoliata subsp. australis (0.921) and A. quinata (0.957) were all greater than 0.9. According to Swets [48], the predictive capacity of the models may be considered excellent if the AUC values were greater than 0.9 . Therefore, we believed that the performances of our models were steady and adequate for construing the potential distribution of these three Akebia taxa.

\subsection{Distribution of the Current Suitable Areas of the Three Akebia Taxa}

The contribution of bioclimatic variables of our species distribution models indicated that temperature (mean diurnal range, isothermality, temperature seasonality and minimum temperature of the coldest month) played a more significant role than precipitation (precipitation of the driest month, precipitation seasonality and precipitation of the warmest quarter) (Table 1, Figure 3). Li Wang et al. [60] analyzed the geographical distribution and various ecological factors of $A$. trifoliata, then selected 16 climatic indicators and determined key climatic variables affecting the growth of $A$. trifoliata by statistical analysis. It was revealed that "heat factor" played the most important role in determining its geographical distribution. Li Lei [61] reported that temperature was the first principal 
component affecting the distribution of A. quinata after evaluating the climatic environment by principal component analysis. Our results corroborated the above findings.

In our study, the dominant bioclimatic variable that affects the distribution of A. trifoliata and A. quinata in China was found to be the minimum temperature of the coldest month (BIO06). For A. trifoliata subsp. australis, the mean diurnal range (BIO02) was the dominant variable influencing its distribution. The change of the minimum temperature of coldest month may result in freezing damage to plants, and continued low temperature may cause the death of plants at the edge of suitable areas [62]. The mean diurnal range reflects the change of temperature in a day, and the photosynthesis and respiration of the plant during the day and night would contribute to the accumulation of nutrients [63]. The change of temperature has an important influence on the growth of plants. Previous reports demonstrated that $A$. trifoliata was resistant to temperatures as low as about $-15^{\circ} \mathrm{C}$, and A. quinata could tolerate temperatures down to approximately $-20^{\circ} \mathrm{C}$ [64]. Compared with the former two taxa, A. trifoliata subsp. australis had lower frost resistance [65]. A similar pattern of results was observed in this study. The moderate- and high-suitability areas of A. trifoliata and A. quinata occurred more widely at $23.5-35.9^{\circ} \mathrm{N}$. However, those of A. trifoliata subsp. australis mainly occurred at $19.3-34.9^{\circ} \mathrm{N}$, which may be related to the different extreme temperatures that these three taxa could tolerate. Further studies are necessary to illuminate the underlying mechanism.

\subsection{Changes on the Future Suitable Areas of the Three Akebia Taxa and Their Implications}

The growth of greenhouse gas emissions caused by human activities has intensified the climate warming and caused changes in the distribution of plants [66]. For this study, the latest CMIP6 data were used to predict the distribution changes of three Akebia taxa under different scenarios (Figures 5-7).

Generally, except for several special situations and periods, the total suitable areas of three Akebia taxa all present an increasing trend in the future, and that trend was mainly reflected in the expansion of low-suitability areas. The increases in low-suitability areas were mainly manifested in two aspects. Firstly, global warming had converted several regions in the northern and western parts of the land area of China from initially unsuitable areas to low-suitability areas. This could probably be explained by the fact that Akebia are thermophilic and that temperature has a great influence on the distribution of Akebia. A previous study showed that global warming would greatly affect the distribution of species by promoting the expansion of suitable areas [67]. Our results corroborated this finding. Secondly, a few moderate- and high-suitability areas were converted into lowsuitability areas under climate change. This phenomenon indicates that climate change restricts the growth of plants in suitable areas, and that global warming could also exert an adverse impact on ecosystems and species by affecting the life activities of plants through photosynthesis and respiration [68]. Many photosynthetic components are highly sensitive to temperature; low temperature would reduce the rate of photosynthesis and high temperature might lead to enzyme degradation [69].

The moderate- and high-suitability areas of these three Akebia taxa were predicted to decrease in different shared socioeconomic scenarios and periods. The reduction was mainly reflected in the shrinking to the core distribution areas, and there was no obvious migration of the centroid of the geographical distribution of Akebia. An important reason was that these core regions are located in areas with diverse ecological environments and complete ecosystems. For example, the Qinling-Daba (Qinba) Mountains region is one of the biodiversity hotspots of China, with a diverse topography and various climatic conditions, and provides desirable habitats for plant growth [70]. The Dabie Mountains area has complex topography and temperate climate, which provide the possibility for the development of species diversity [71]. A further novel finding was that the distribution of the moderate-suitability area of A. trifoliata and the high- and moderate-suitability areas of A. quinata were fragmented in central China and the Yangtze River Basin. It is speculated 
that the land use change caused by human activities, e.g., the rapid and intensive expansion of agriculture, in turn leads to the fragmentation of the habitats [36,72].

By analyzing the distribution of low-impact areas of these three Akebia taxa under different climatic scenarios, it was found that with the increase in radiative forcing of SSP, the low-impact areas would decrease gradually (Table 3). This trend involves both physical factors (incl. radiative forcing) and anthropological factors (e.g., social and economic development and demographic change). SSP1, SSP2, SSP3 and SSP5 represent societies that take the green road, the middle road, a rocky road, and the highway. The more friendly a social environment is, the larger the suitable area will be. It should be noted that as the subspecies of A. trifoliata, A. trifoliata subsp. australis possess different characters in terms of the shape of lobules [36], its potential distribution was relatively more southward, but the morphological difference was not a sufficient reason to explain the differences in distribution. Perhaps in the future, an analysis of physiological functions could be applied to settle this issue. In addition, according to field investigation and literature reports, the distribution of Akebia has shrunk and fragmented, with this being the result of a combination of human interference and climate change [36,73]. Our study focused on the climate suitability of these three Akebia taxa; the actual suitable areas would be smaller in the future due to the influence of other factors, e.g., soil properties and land use change $[74,75]$. Bioclimate variables alone may not accurately predict the future distribution of species; more factors, such as human footprint indices, land use data and edaphic factors, should be considered to improve the accuracy of species distribution predictions in the future. Our results could serve as theoretical basis to protect the sustainable utilization of Akebia's resources by identifying regions where Akebia is more likely to thrive in the future.

\section{Conclusions}

For this study, the potential distributions of three Akebia taxa were predicted using the MAXENT model in four periods and under four shared socioeconomic pathways. Under the current climate condition, the suitable areas of these three Akebia taxa were mainly distributed in China at $101.8-121.9^{\circ} \mathrm{E}$ and $23.5-34.6^{\circ} \mathrm{N}$. Temperature is considered to play a more significant role than precipitation. The dominant bioclimatic variable affecting the distribution of $A$. trifoliata and A. quinata in China was found to be the minimum temperature of the coldest month (BIO06). For A. trifoliata subsp. australis, the mean diurnal range (BIO02) was identified as the most important variable influencing its distribution. The low-suitability areas of these three Akebia taxa were all observed to increase under different climate change scenarios, and their moderate- and high-suitability areas were predicted to contract towards the core in the future compared with their respective current areas. As for low-impact areas, with the increase in the radiative forcing of SSP, the low-impact areas of these three Akebia taxa would decrease gradually. This study clearly describes the potential distribution of Akebia under climate change scenarios in China, and thus, provides a theoretical basis for the protective exploitation of wild resources and the establishment of new cultivations.

Author Contributions: Conceptualization, Z.Z.; methodology, X.W.; software, X.W. and W.Z.; validation, X.Z. and H.Z.; formal analysis, Z.Q.; investigation, X.W., X.Z. and H.Z.; resources, X.Z. and L.M.; data curation, X.W.; writing-original draft preparation, X.W. and W.Z.; writing-review and editing, Z.Q., Z.Z. and X.W.; visualization, X.W.; supervision, Z.Z.; project administration, Z.Z.; funding acquisition, Z.Z. All authors have read and agreed to the published version of the manuscript.

Funding: This research was funded by the General Program of Science and Technology of Shaanxi Province, China, grant number 2021JM-199.

Data Availability Statement: The data presented in this study are available on request from the corresponding author.

Conflicts of Interest: The authors declare no conflict of interest. 


\section{References}

1. IPCC. Summary for Policymakers. In Climate Change 2021: The Physical Science Basis. Contribution of Working Group I to the Sixth Assessment Report of the Intergovernmental Panel on Climate Change; Intergovernmental Panel on Climate Change: Cambridge, UK; New York, NY, USA, 2021.

2. Parmesan, C.; Yohe, G. A globally coherent fingerprint of climate change impacts across natural systems. Nat. Cell Biol. 2003, 421, 37-42. [CrossRef] [PubMed]

3. Grimm, N.B.; Faeth, S.H.; Golubiewski, N.E.; Redman, C.L.; Wu, J.; Bai, X.; Briggs, J.M. Global Change and the Ecology of Cities. Science 2008, 319, 756-760. [CrossRef]

4. Urban, M.C. Accelerating extinction risk from climate change. Science 2015, 348, 571-573. [CrossRef] [PubMed]

5. Ying, Z. Projections of $2{ }^{\circ} \mathrm{C}$ warming over the globe and China under RCP4.5. Atmos. Ocean. Sci. Lett. 2012, 5, 514-520. [CrossRef]

6. Zhao, D.S.; Gao, X.; Wu, S.G.; Zheng, D. Trend of climate variation in China from 1960 to 2018 based on natural regionalization. Adv. Earth Sci. 2020, 35, 750-760.

7. Barnosky, A.D.; Matzke, N.; Tomiya, S.; Wogan, G.O.U.; Swartz, B.; Quental, T.B.; Marshall, C.; McGuire, J.L.; Lindsey, E.L.; Maguire, K.C.; et al. Has the Earth's sixth mass extinction already arrived? Nature 2011, 471, 51-57. [CrossRef] [PubMed]

8. Jin, K.; Wang, F.; Li, P. Responses of Vegetation Cover to Environmental Change in Large Cities of China. Sustainability 2018, 10, 270. [CrossRef]

9. Piao, S.; Yin, G.; Tan, J.; Cheng, L.; Huang, M.; Li, Y.; Liu, R.; Mao, J.; Myneni, R.B.; Peng, S.; et al. Detection and attribution of vegetation greening trend in China over the last 30 years. Glob. Chang. Biol. 2015, 21, 1601-1609. [CrossRef]

10. Jiang, M.; Tian, S.; Zheng, Z.; Zhan, Q.; He, Y. Human Activity Influences on Vegetation Cover Changes in Beijing, China, from 2000 to 2015. Remote Sens. 2017, 9, 271. [CrossRef]

11. Pan, Y.; Birdsey, R.A.; Fang, J.; Houghton, R.; Kauppi, P.E.; Kurz, W.A.; Phillips, O.L.; Shvidenko, A.; Lewis, S.L.; Canadell, J.G.; et al. A Large and Persistent Carbon Sink in the World's Forests. Science 2011, 333, 6045. [CrossRef]

12. Oliver, T.; Hill, J.K.; Thomas, C.D.; Brereton, T.; Roy, D.B. Changes in habitat specificity of species at their climatic range boundaries. Ecol. Lett. 2009, 12, 1091-1102. [CrossRef]

13. Weng, Y.W.; Cai, W.J.; Wang, C. The application and future directions of the Shared Socioeconomic Pathways (SSPs). Adv. Clim. Chang. Res. 2020, 16, 215-222.

14. DeMarche, M.L.; Doak, D.F.; Morris, W.F. Incorporating local adaptation into forecasts of species' distribution and abundance under climate change. Glob. Chang. Biol. 2019, 25, 775-793. [CrossRef] [PubMed]

15. Coro, G.; Vilas, L.G.; Magliozzi, C.; Ellenbroek, A.; Scarponi, P.; Pagano, P. Forecasting the ongoing invasion of Lagocephalus sceleratus in the Mediterranean Sea. Ecol. Model. 2018, 371, 37-49. [CrossRef]

16. Elith, J.; Phillips, S.J.; Hastie, T.; Dudík, M.; Chee, Y.E.; Yates, C.J. A statistical explanation of MaxEnt for ecologists. Divers. Distrib. 2011, 17, 43-57. [CrossRef]

17. Hirzel, A.H.; Hausser, J.; Chessel, D.; Perrin, N. Ecological-Niche Factor Analysis: How to Compute Habitat-Suitability Maps without Absence Data? Ecology 2002, 83, 2027-2036. [CrossRef]

18. Beaumont, L.J.; Hughes, L.; Poulsen, M. Predicting species distributions: Use of climatic parameters in BIOCLIM and its im-pact on predictions of species' current and future distributions. Ecol. Model. 2005, 186, 251-270. [CrossRef]

19. Sánchez, F.E. GARP modeling of natural and human factors affecting the potential distribution of the invasives Schismus ara-bicus and Brassica tournefortii, in 'El Pinacate y Gran Desierto de Altar' Biosphere Reserve. Ecol. Model. 2007, 204, 457-474. [CrossRef]

20. Phillips, S.J.; Anderson, R.P.; Schapire, R.E. Maximum entropy modeling of species geographic distributions. Ecol. Model. 2006, 190, 231-259. [CrossRef]

21. Lawler, J.J.; White, D.; Neilson, R.P.; Blaustein, A.R. Predicting climate-induced range shifts: Model differences and model reliability. Glob. Chang. Biol. 2006, 12, 1568-1584. [CrossRef]

22. Li, Y.; Li, M.; Li, C.; Liu, Z. Optimized Maxent Model Predictions of Climate Change Impacts on the Suitable Distribution of Cunninghamia lanceolata in China. Forests 2020, 11, 302. [CrossRef]

23. Dyderski, M.K.; Paź, S.; Frelich, L.E.; Jagodziński, A.M. How much does climate change threaten European forest tree species distributions? Glob. Chang. Biol. 2018, 24, 1150-1163. [CrossRef] [PubMed]

24. Elith, J.; Graham, C.H.; Anderson, R.P.; Dudík, M.; Ferrier, S.; Guisan, A.; Hijmans, R.J.; Huettmann, F.; Leathwick, J.R.; Lehmann, A.; et al. Novel methods improve prediction of species' distributions from occurrence data. Ecography 2006, 29, 129-151. [CrossRef]

25. Farashi, A.; Alizadeh-Noughani, M. Effects of models and spatial resolutions on the species distribution model performance. Model. Earth Syst. Environ. 2018, 4, 263-268. [CrossRef]

26. Rong, Z.; Zhao, C.; Liu, J.; Gao, Y.; Zang, F.; Guo, Z.; Mao, Y.; Wang, L. Modeling the effect of climate change on the poten-tial distribution of Qinghai spruce (Picea crassifolia Kom.) in Qilian Mountains. Forests 2019, 10, 62. [CrossRef]

27. Puchałka, R.; Dyderski, M.K.; Vítková, M.; Sádlo, J.; Klisz, M.; Netsvetov, M.; Prokopuk, Y.; Matisons, R.; Mionskowski, M.; Wojda, T.; et al. Black locust (Robinia pseudoacacia L.) range contraction and expansion in Europe under changing climate. Glob. Chang. Biol. 2021, 27, 1587-1600. [CrossRef]

28. Zhao, R.; Chu, X.; He, Q.; Tang, Y.; Song, M.; Zhu, Z. Modeling Current and Future Potential Geographical Distribution of Carpinus tientaiensis, a Critically Endangered Species from China. Forests 2020, 11, 774. [CrossRef]

29. Santos-Hernández, A.F.; Monterroso-Rivas, A.I.; Granados-Sánchez, D.; Villanueva-Morales, A.; Santacruz-Carrillo, M. Projections for Mexico's tropical rainforests considering ecological niche and climate change. Forests 2021, 12, 119. [CrossRef] 
30. Editorial Commission of Chinese Flora of Chinese Academy of Sciences. Flora of China; Science Press: Beijing, China, 2001; Volume 29, pp. 4-5.

31. Chinese Pharmacopoeia Commission. Pharmacopoeia of the People's Republic of China; China Medical Science Press: Beijing, China, 2020.

32. Liu, Y.; Hou, X.; Xie, Y.; Feng, Y.; Ou, Y.; Yang, S. Overview of research on chemical constituents and pharmacological activ-ities of Akebia Dence. J. Jiangxi Univ. Trad. Chin. Med. 2012, 24, 87-93.

33. An, J.-P.; Ha, T.K.Q.; Kim, J.; Cho, T.O.; Oh, W.K. Protein tyrosine phosphatase 1B inhibitors from the stems of Akebia quinata. Molecules 2016, 21, 1091. [CrossRef]

34. Peng, P.; Jia, D.; Cao, L.; Lu, W.; Liu, X.; Liang, C.; Pan, Z.; Fang, Z. Akebia saponin E, as a novel PIKfyve inhibitor, induces lysosome-associated cytoplasmic vacuolation to inhibit proliferation of hepatocellular carcinoma cells. J. Ethnopharmacol. 2021, 266, 113446. [CrossRef]

35. Lu, W.-L.; Yang, T.; Song, Q.-J.; Fang, Z.-Q.; Pan, Z.-Q.; Liang, C.; Jia, D.-W.; Peng, P.-K. Akebia trifoliata (Thunb.) Koidz Seed Extract inhibits human hepatocellular carcinoma cell migration and invasion in vitro. J. Ethnopharmacol. 2019, 234, 204-215. [CrossRef]

36. Li, L.; Chen, X.-Z.; Yao, X.-H.; Tian, H.; Huang, H.-W. Geographic Distribution and Resource Status ofThree Important Akebia Species. Plant Sci. J. 2010, 30, 497-506. [CrossRef]

37. Phillips, S.J.; Dudík, M.; Elith, J.; Graham, C.H.; Lehmann, A.; Leathwick, J.; Ferrier, S. Sample selection bias and pres-ence-only distribution models: Implications for background and pseudo-absence data. Ecol. Appl. 2009, 19, 181-197. [CrossRef]

38. Warren, D.L.; Glor, R.; Turelli, M. ENMTools: A toolbox for comparative studies of environmental niche models. Ecography 2010, 33, 607-611. [CrossRef]

39. Fick, S.E.; Hijmans, R.J. WorldClim 2: New 1-km spatial resolution climate surfaces for global land areas. Int. J. Climatol. 2017, 37, 4302-4315. [CrossRef]

40. Sillero, N. What does ecological modelling model? A proposed classification of ecological niche models based on their under-lying methods. Ecol. Model. 2011, 222, 1343-1346.

41. Su, B.; Huang, J.; Mondal, S.K.; Zhai, J.; Wang, Y.; Wen, S.; Gao, M.; Lv, Y.; Jiang, S.; Jiang, T.; et al. Insight from CMIP6 SSP-RCP scenarios for future drought characteristics in China. Atmos. Res. 2021, 250, 105375. [CrossRef]

42. Editorial. The CMIP6 landscape. Nat. Clim. Chang. 2019, 9, 727.

43. Wei, J.; Li, X.; Lu, Y.; Zhao, L.; Zhang, H.; Zhao, Q. Modeling the Potential Global Distribution of Phenacoccus madeirensis Green under Various Climate Change Scenarios. Forests 2019, 10, 773. [CrossRef]

44. Guisan, A.; Graham, C.H.; Elith, J.; Huettmann, F.; the NCEAS Species Distribution Modelling Group. Sensitivity of predic-tive species distribution models to change in grain size. Divers. Distrib. 2007, 13, 332-340. [CrossRef]

45. Morales, N.S.; Fernández, I.C.; Baca-González, V. MaxEnt's parameter configuration and small samples: Are we paying at-tention to recommendations? A systematic review. PeerJ 2017, 5, e3093.

46. Cobos, M.E.; Townsend Peterson, A.; Barve, N.; Osorio-Olvera, L. Kuenm: An R package for detailed development of ecological niche models using Maxent. PeerJ 2019, 7, e6281. [CrossRef] [PubMed]

47. Angelieri, C.C.; Adams-Hosking, C.; Ferraz, K.M.; de Souza, M.P.; McAlpine, C.A. Using species distribution models to pre-dict potential landscape restoration effects on Puma conservation. PLoS ONE 2016, 11, e0145232. [CrossRef]

48. Swets, J.A. Measuring the accuracy of diagnostic systems. Science 1988, 240, 1285-1293. [CrossRef] [PubMed]

49. Peterson, A.T.; Papeş, M.; Soberon, J. Rethinking receiver operating characteristic analysis applications in ecological niche modeling. Ecol. Model. 2008, 213, 63-72. [CrossRef]

50. Osorio-Olvera, L.; Lira-Noriega, A.; Soberón, J.; Townsend Peterson, A.; Falconi, M.; Contreras-Díaz, R.G.; Martínez-Meyer, E.; Barve, V.; Barve, N. ntbox: An r package with graphical user interface for modelling and evaluating multidimensional ecological niches. Methods Ecol. Evol. 2020, 11, 1199-1206. [CrossRef]

51. Fuentes, M.M.P.B.; Allstadt, A.J.; Ceriani, S.A.; Godfrey, M.H.; Gredzens, C.; Helmers, D.; Ingram, D.; Pate, M.; Radeloff, V.C.; Shaver, D.J.; et al. Potential adaptability of marine turtles to climate change may be hindered by coastal development in the USA. Reg. Environ. Chang. 2020, 20, 104. [CrossRef]

52. Warren, D.L.; Seifert, S.N. Ecological niche modeling in MaxEnt: The importance of model complexity and the performance of model selection criteria. Ecol. Appl. 2011, 21, 335-342. [CrossRef]

53. Kong, W.; Li, X.; Zou, H. Optimizing MaxEnt model in the prediction of species distribution. Chin. J. Appl. Ecol. 2019, 30, 2116-2128.

54. Hernandez, P.A.; Graham, C.H.; Master, L.L.; Albert, D.L. The effect of sample size and species characteristics on performance of different species distribution modeling methods. Ecography 2006, 29, 773-785. [CrossRef]

55. Hirzel, A.; Guisan, A. Which is the optimal sampling strategy for habitat suitability modelling. Ecol. Model. 2002, 157, 331-341. [CrossRef]

56. Kramer-Schadt, S.; Niedballa, J.; Pilgrim, J.D.; Schröder, B.; Lindenborn, J.; Reinfelder, V.; Stillfried, M.; Heckmann, I.; Scharf, A.K.; Augeri, D.M.; et al. The importance of correcting for sampling bias in MaxEnt species distribution models. Divers. Distrib. 2013, 19, 1366-1379. [CrossRef]

57. Baldwin, R.A. Use of Maximum Entropy Modeling in Wildlife Research. Entropy 2009, 11, 854-866. [CrossRef]

58. Phillips, S.J.; Dudik, M. Modeling of species distributions with MaxEnt: New extensions and a comprehensive evaluation. Ecography 2008, 31, 161-175. [CrossRef] 
59. Radosavljevic, A.; Robert, P.A. Making better MAXENT models of species distributions: Complexity, overfitting and evaluation. J. Biogeogr. 2014, 41, 629-643. [CrossRef]

60. Wang, L.; Deng, H.G.; Qiu, X.F.; Wang, P.F.; Yang, F. Determining the impact of key climatic factors on geographic distribu-tion of wild Akebia trifoliate. Ecol. Indic. 2020, 112, 106093. [CrossRef]

61. Li, L. Study on the Resource and Quality Evaluation of Akebia Quinata in Anhui Province. Master's Thesis, Anhui University of Traditional Chinese Medicine, Hefei, China, 2018.

62. Harsch, M.A.; HilleRisLambers, J. Climate Warming and Seasonal Precipitation Change Interact to Limit Species Distribution Shifts across Western North America. PLoS ONE 2016, 11, e0159184. [CrossRef]

63. Bachman, G.R.; McMahon, M.J. Day and night temperature differential (DIF) or the absence of far-red light alters cell elonga-tion in 'Celebrity White' Petunia. J. Amer. Soc. Hort. Sci. 2006, 131, 309-312. [CrossRef]

64. Christenhusz, M.J.M.; Rix, M. Akebia quinata. Curtis's Bot. Mag. 2012, 29, 284-289. [CrossRef]

65. Li, L.; Yao, X.; Zhong, C.; Chen, X.; Huang, H. Akebia: A Potential New Fruit Crop in China. HortScience 2010, 45, 4-10. [CrossRef]

66. Wang, C.; Shi, X.; Liu, J.; Zhao, J.; Bo, X.; Chen, F.; Chu, Q. Interdecadal variation of potato climate suitability in China. Agric. Ecosyst. Environ. 2021, 310, 107293. [CrossRef]

67. Li, Y.; Zhang, C.; Zhu, H.; Li, X.; Duan, Y.; Wang, X. Analyses on suitable distribution areas and main climatic variables of Osmanthus yunnanensis and O. delavayi. J. Plant Resour. Environ. 2019, 55, 71-78.

68. Moore, C.E.; Meacham-Hensold, K.; Lemonnier, P.; Slattery, R.A.; Benjamin, C.; Bernacchi, C.J.; Lawson, T.; Cavanagh, A.P. The effect of increasing temperature on crop photosynthesis: From enzymes to ecosystems. J. Exp. Bot. 2021, 72, 2822-2844. [CrossRef] [PubMed]

69. Prasad, P.V.V.; Djanaguiraman, M. High night temperature decreases leaf photosynthesis and pollen function in grain sor-ghum. Funct. Plant Biol. 2011, 38, 993-1003. [CrossRef]

70. Li, X.; Ma, B.; Lu, C.; Yang, H.; Sun, M. Spatial Pattern and Development of Protected Areas in the North-south Transitional Zone of China. Chin. Geogr. Sci. 2021, 31, 149-166. [CrossRef]

71. Fang, Y.; Cai, S.; Xiang, J.; Zhong, Y.; Hu, Y.; Xia, X. Biodiversity of Dabieshan in eastern Hubei Province and its protection strategy. J. Anhui Agri. Sci. 2007, 35, 5246-5248.

72. Haddad, N.M.; Brudvig, L.A.; Clobert, J.; Davies, K.F.; Gonzalez, A.; Holt, R.D.; Lovejoy, T.E.; Sexton, J.O.; Austin, M.P.; Collins, C.D.; et al. Habitat fragmentation and its lasting impact on Earth's ecosystems. Sci. Adv. 2015, 1, e1500052. [CrossRef]

73. Zhang, Y.J.; Dang, H.S.; Yang, L.L.; Wei, G.Y.; Wang, Y. Geographical distribution and resource survey of wild medicinal plant Akebia trifoliata subsp. trifoliata. Chin. Wild Plant Resour. 2013, 32, 58-62.

74. Hageer, Y.; Esperón-Rodríguez, M.; Baumgartner, J.B.; Beaumont, L.J. Climate, soil or both? Which variables are better pre-dictors of the distributions of Australian shrub species? PeerJ 2017, 5, e3446. [CrossRef]

75. Milanesi, P.; Della Rocca, F.; Robinson, R.A. Integrating dynamic environmental predictors and species occurrences: Toward true dynamic species distribution models. Ecol. Evol. 2019, 10, 1087-1092. [CrossRef] [PubMed] 